\title{
Effect of obturation technique using a new bioceramic sealer on the presence of voids in flattened root canals
}

\author{
Airton Oliveira \\ SANTOS-JUNIOR(a) \\ Mário TANOMARU-FILHO(a) \\ Jáder Camilo PINTO(a) \\ Karina Ines Medina Carita \\ TAVARES(a) \\ Fernanda Ferrari Esteves \\ TORRES(a) \\ Juliane Maria \\ GUERREIRO-TANOMARU(a) \\ (a) Universidade Estadual Paulista - Unesp, \\ School of Dentistry, Department of \\ Restorative Dentistry, Araraquara, SP, Brazil.
}

Declaration of Interests: The authors certify that they have no commercial or associative interest that represents a conflict of interest in connection with the manuscript.

Mario Tanomaru-Filho

E-mail: tanomaru@uol.com.br

ht1ps://doi.org/10.1590/1807-3107bor-2021.vol35.0028

Submitted: May 23, 2020

Accepted for publication: November 19, 2020

Last revision: November 30, 2020

\begin{abstract}
The aim of this study was to evaluate the filling ability of a new ready-to-use calcium silicate-based sealer using thermoplastic or single-cone technique in flattened root canals. Twenty-four flattened distal canals of mandibular molars with a buccolingual diameter 4 or more times larger than the mesiodistal diameter were selected. The root canals were prepared and filled ( $\mathrm{n}=12)$, according to the following techniques: thermoplastic or single-cone technique using Bio-C Sealer. The teeth were scanned using Skycan 1176 micro-computed tomography (micro-CT) - voxel size $8.74 \mu \mathrm{m}$, before and after filling the root canal. The percentage of voids in the filled root canals was evaluated, and the data were statistically analyzed using the unpaired t-test $(\alpha=0.05)$. The root canals filled using the thermoplastic technique created a smaller percentage of voids in the cervical/middle thirds than those filled using the single-cone technique $(\mathrm{p}<0.05)$. There was no difference in the percentage of voids using either technique in the apical third ( $p>0.05)$. The flattened root canals in the cervical/middle thirds were better filled using the ready-to-use calcium silicate-based sealer associated to the thermoplastic technique, compared with the single-cone technique. In the apical third, the techniques showed similar filling ability.
\end{abstract}

Keywords: Endodontics; Root Canal Filling Materials; Root Canal Obturation; X-Ray Microtomography.

\section{Introduction}

The prognosis of endodontic treatment depends on three-dimensional filling $^{1,2}$ and sealing of the root canal system, ${ }^{3}$ to ensure prevention of reinfection. ${ }^{4}$ However, the quality of the filling is influenced by root canal morphology. $1,3,4,5,6$ Root canals with a large buccolingual extension are more difficult to fill. 1,3,4,5,6 Moreover, the centric position obtained by nickel-titanium (NiTi) instruments leaves a considerable uninstrumented surface in flattened areas, ${ }^{7,8,9}$ thereby affecting the quality of root canal fillings. ${ }^{1,3,5}$ Although some studies have evaluated the obturation of oval canals, ${ }^{1,3,4,5,6}$ the literature is very scarce regarding the filling of flattened canals with a buccolingual diameter 4 or more times larger than the mesiodistal diameter.

Different obturation techniques have been proposed for filling the root canal system. . $^{3,410,11,12}$ However, none of them fill the entire extension of the canal. ${ }^{3,4,10,11,12}$ Thermoplastic filling techniques have been 
developed to improve filling procedures in flattened areas. ${ }^{3,12}$ Tagger's hybrid technique associates lateral condensation in the apical third and thermomechanical compaction of the filling material in the cervical and middle thirds of the root canal. ${ }^{13}$ Greater homogeneity of the filling mass as well as the filling in the apical third has been achieved better with the thermoplastic than the lateral condensation technique. ${ }^{14}$ When Tagger's hybrid technique was used, a larger area of gutta-percha was observed in the cervical and middle thirds, in comparison with the lateral condensation and the GuttaFlow techniques. ${ }^{10}$ Tagger's hybrid technique has shown filling ability similar to that of continuous wave condensation and Thermafil in oval root canals. ${ }^{4}$ However, the thermoplastic filling technique has shown a higher risk of filling material extrusion than the cold gutta-percha technique. ${ }^{15}$

The single-cone technique is frequently used for filling root canals, ${ }^{1,5,16,17}$ because of its simplicity and speed, ${ }_{1}^{16}$ and also because it is less operator-dependent. ${ }^{17}$ This filling technique uses a gutta-percha cone with a diameter similar to that of the last NiTi instrument used in preparing root canals. ${ }^{1,16}$ The single-cone technique was found to be similar to Thermafil and System B thermoplastic techniques in straight canals. ${ }^{18}$ In addition, it showed marginal adaptation at the sealer/dentin interface similar to that of the thermoplastic technique in mesial root canals of mandibular molars. ${ }^{19}$ However, since the single-cone technique demands a greater amount of sealer, the flowability and other physicochemical properties of the sealer play an essential role in the success of endodontic treatment. ${ }^{16}$

Root canal sealers based on calcium silicates have been proposed, owing to their biocompatibility, bioactivity ${ }^{20}$ and antibacterial effect. ${ }^{21} \mathrm{New}$ premixed ready-to-use calcium silicate sealers have recently been developed, such as Bio-C Sealer (Angelus, Londrina, Brazil). Bio-C Sealer has radiopacity, alkalization capability and higher flow than TotalFill BC Sealer (FKG Dentaire SA, La Chaux-de-Fonds, Switzerland) and AH Plus (Dentsply DeTrey, Konstanz, Germany), ${ }^{22}$ thus allowing it to fill anatomical complexities, ${ }^{23}$ such as flattened root canals.

There are no studies related to the filling ability of premixed ready-to-use calcium silicate-based sealers in flattened root canals. Therefore, the aim of this study was to compare the percentage of voids in flattened root canals filled with Bio-C Sealer using the thermoplastic or the single-cone technique, as scanned by micro-computed tomography (micro-CT). The null hypothesis tested was that there would be no difference in the quantity of voids in flattened root canals filled with Bio-C, using either technique.

\section{Methodology}

\section{Sample size calculation}

The sample calculation was performed using the $G^{*}$ Power 3.1.7 for Windows (Heinrich Heine, Universität Dusseldorf, Germany). The t-test of two independent groups was applied with an alpha type error of 0.05 and beta power of 0.95 . The effect size of 1.54 was determined based on a previous study that used a similar methodology. ${ }^{3}$ The advisable specimen size was 12 per group.

\section{Sample selection}

After approval by the local ethics committee (under number 98683818.0.0000.5416), 24 distal canals of mandibular molars were selected by a digital radiography system (Kodak RVG 6100, Marne-la-Vallée, France) and micro-CT (Skyscan 1176, Bruker-microCT, Kontich, Belgium). Initial scanning by micro-CT was performed with a voxel size of $35 \mu \mathrm{m}$, with the following parameters: copper and aluminum filter, exposure time of $87 \mathrm{~ms}$, frame averaging 3, rotation $180^{\circ}$, rotation step of $0.5,80 \mathrm{kV}$ and $300 \mathrm{uA}$. The selected root canals had a type I configuration according to the Vertucci ${ }^{24}$ classification, and presented with flattening, in which the diameter ratio was obtained when the buccolingual diameter was 4 or more times larger than the mesiodistal diameter ${ }^{25}$ at $9 \mathrm{~mm}$ from the radiographic apex. ${ }^{26}$

\section{Root canal preparation}

Conventional access cavities were prepared, and the canals were explored with a size $10 \mathrm{~K}$-file (Dentsply Maillefer, Ballaigues, Switzerland) until their tip became visible in the apical foramen. The working length (WL) was established $1.0 \mathrm{~mm}$ short of the apical foramen. The root canals were prepared with 
the Reciproc Blue R40 file (VDW, Munich, Germany). The instruments were driven by an electric motor (VDW Silver, Munich, Germany) in the "RECIPROC ALL" function, according to the manufacturer's instructions, up to the WL. Root canal irrigation during preparation was performed with $6 \mathrm{~mL}$ of $2.5 \%$ sodium hypochlorite $(\mathrm{NaOCl})(2 \mathrm{~mL}$ for each third). A 30-G NaviTip needle (Ultradent Products, South Jordan, USA) was coupled to a $5 \mathrm{~mL}$ syringe, and placed up to $2 \mathrm{~mm}$ short of the WL.

A complementary preparation was performed using a Flatsonic ultrasonic tip (Helse Ultrasonic, Santa Rosa de Viterbo, Brazil) activated by an Ultrawave XS (Ultradent) appliance at a power of $25 \%$ and frequency of $50 \mathrm{~Hz}$. The ultrasonic tip was activated for 3 cycles, each cycle lasting 30 seconds in the direction of each flattened region (buccal and lingual). A total of $3 \mathrm{~mL}$ of $2.5 \% \mathrm{NaOCl}$ was used $(1.5 \mathrm{~mL}$ before and $1.5 \mathrm{~mL}$ after each cycle) for each ultrasound cycle. Final irrigation of each sample was performed with $5 \mathrm{~mL}$ $2.5 \% \mathrm{NaOCl}$, followed by $2 \mathrm{~mL} 17 \%$ EDTA and $5 \mathrm{~mL}$ of distilled water.

\section{Root canal filling}

After root canal preparation, the specimens were divided into two experimental groups $(n=12)$ according to simple stratified randomization, considering the post-preparation volume of the root canal, in order to allow similar distribution between groups. The root canals were filled with Bio-C Sealer using the thermoplastic or the single-cone technique. R40 (VDW) gutta-percha points were selected according to tip size and taper, as measured by a Profilometer appliance (Profile Projector Nikon model 6C-2, Nikon, Tokyo, Japan). Prior to the canal filling stage, radiographic proof was obtained of adaptation of the gutta-percha points in the root canals. For the two filling techniques, Bio-C Sealer was injected into the root canal up to $4 \mathrm{~mm}$ short of the $\mathrm{WL}$, using plastic syringes and needles provided by the manufacturer.

\section{Thermoplastic technique}

The gutta-percha master point coated with sealer was inserted into the canal up to the WL. Lateral condensation was performed in the apical third with a size 25 finger spreader (Dentsply Maillefer) and 4 XF accessory gutta-percha points (Dentsply Maillefer). Lateral condensation was performed in the cervical and middle thirds with a size 30 finger spreader and 4 FF accessory gutta-percha points. Gutta-percha condenser (Dentsply Maillefer) size 50 was activated at the beginning of the cervical third in a clockwise direction at $8000 \mathrm{rpm}$. When the gutta-percha began to plasticize, the condenser was directed to $4 \mathrm{~mm}$ short of the $\mathrm{WL}$, and then slowly removed against one of the root canals walls.

\section{Single-cone technique}

After the root canal sealer was inserted, the guttapercha point coated with sealer was inserted into the canal up to the WL.

The procedure for the two experimental groups consisted of cutting and compacting the coronal excess of gutta-percha with a \# 2 heat plugger (Golgran, São Caetano do Sul, Brazil). Digital radiographs were taken in the buccolingual and mesiodistal directions to determine the quality of the fillings. The root canals were restored with Coltosol (Vigodent, Rio de Janeiro, Brazil) and stored at $37^{\circ} \mathrm{C}$ and $95 \%$ relative humidity for 1 week to allow complete setting of the sealer.

\section{Micro-CT analysis}

The samples were scanned using Skycan 1176 micro-CT before and after preparation, and after filling, using the following parameters: $80 \mathrm{kV}$, $300 \mathrm{uA}, 0.5$ rotation step, frame averaging 4 , copper and aluminum filter, exposure time of $2000 \mathrm{~ms}$ and voxel size of $8.74 \mu \mathrm{m}$. The methodology is represented in Figure 1. The images obtained were reconstructed with NRecon software (v.1.6.3, Bruker-microCT). Geometric alignment using the "3D registration" function of the Data Viewer software (v.1.5.1, Bruker-microCT) was performed to superimpose the specimens before and after filling. Both the root canal volume after preparation and the filling material volume were quantified using CTAn software (v.1.14.4, BrukermicroCT). Three dimensional models were created by CTVox software (v.3.2, Bruker-microCT). The gray scale interval for identifying each object of study was determined with a density histogram by using adaptive thresholding. To obtain the percentage of voids, the post-preparation volume of the canal and 
the volume of filling material were calculated by using the following formula: [Percentage of voids $=100$ (filling material volume $\times 100$ / canal volume)]. The analyses were performed in the cervical/middle and apical thirds of the root canals. The values considered were $3 \mathrm{~mm}$ for the apical third and $6 \mathrm{~mm}$ for the cervical/middle thirds. In the CTAn software, the bottom value was defined as the WL for the apical third. Another $3 \mathrm{~mm}$ was added to this value to ultimately define the top. As for the cervical/middle thirds, the top of the apical third was considered the bottom value, and $6 \mathrm{~mm}$ were added to define the top.
A
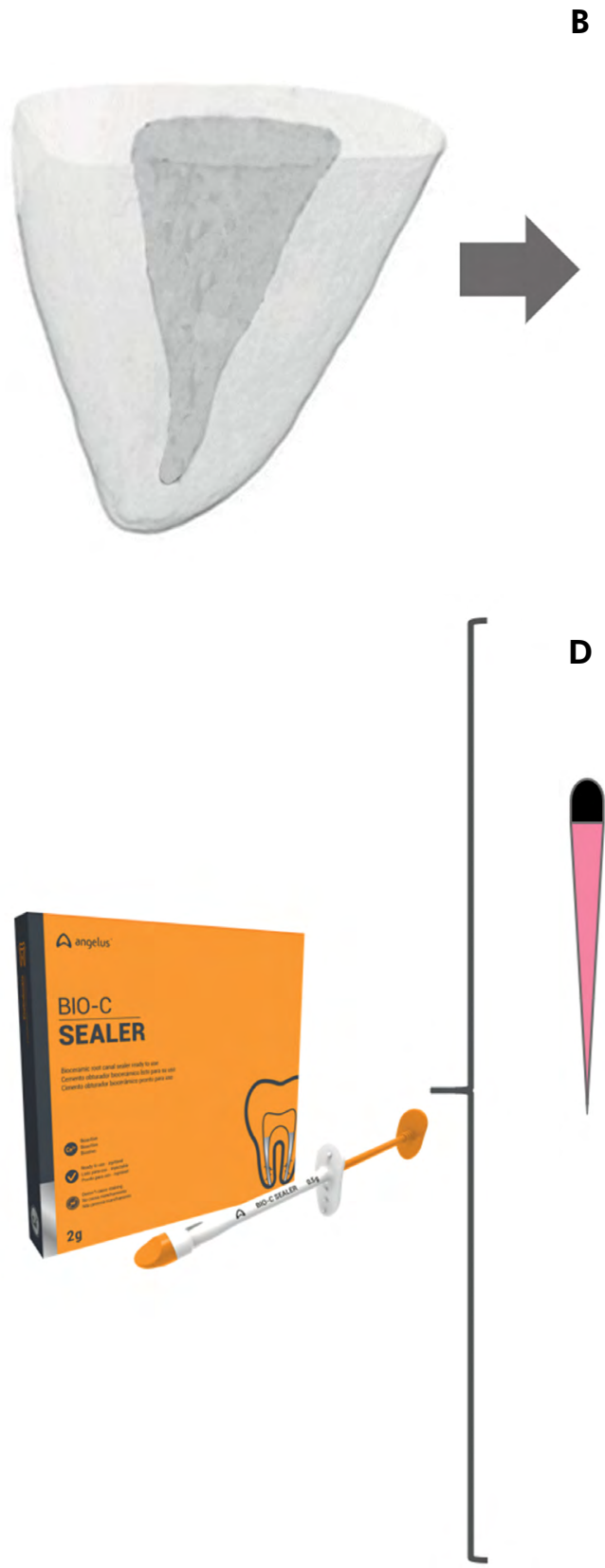

B

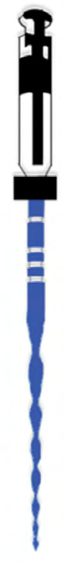

D

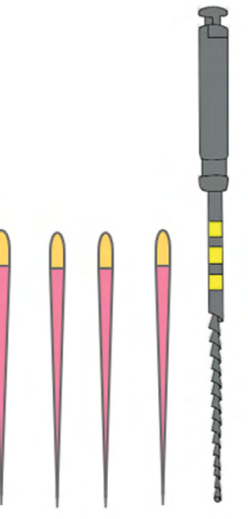

C
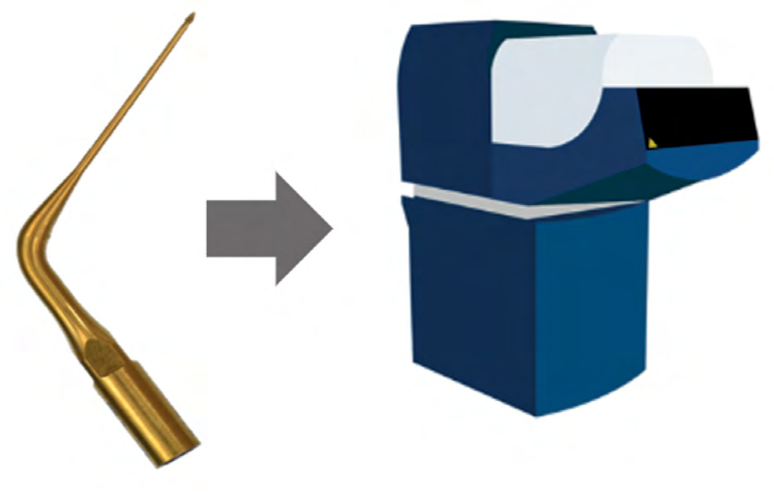

E

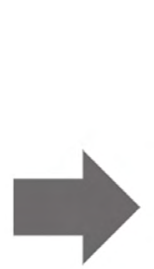

Figure 1. Schematic figure representing the methodology. (a) Flattened distal root canal of a mandibular molar; (b) Root canal preparation with Reciproc Blue R40 and Flatsonic; (c) Scanning with micro-CT - $8.74 \mu \mathrm{m}$; (d) Root canal filling with Bio-C Sealer using thermoplastic or single-cone techniques; (e) Scanning with micro-CT - $8.74 \mu \mathrm{m}$ to evaluate the percentage of voids. 


\section{Statistical analysis}

Normal distribution of data was confirmed by the Shapiro-Wilk test. The unpaired t-test was used to compare the results between the groups. The level of significance was set at $\mathrm{p}<0.05$.

\section{Results}

The thermoplastic technique had a lower percentage of voids in the cervical/middle thirds, in comparison with the single-cone technique $(\mathrm{p}<0.05)$. However, there was no difference between the techniques in regard to the percentage of voids in the apical third $(p>0.05)$ (Figures 2 and 3). The results are described in Table.

\section{Discussion}

Several studies have reported that canals with large buccolingual extensions are difficult to fill adequately. ${ }^{1,3,4,5,6} \mathrm{An}$ important factor for appropriate filling by gutta-percha and root canal sealers is the root canal preparation. ${ }^{27}$ Previous studies have reported that the mechanical effect of ultrasonic tips in oval and long oval canal preparation may optimize their cleaning, by decreasing the uninstrumented surface. ${ }^{8,28}$ To this end, the present study used a Flatsonic ultrasonic tip to improve cleaning of the flattened root canals, by allowing better adaptation of the filling material. In addition, the current study used micro-CT analysis, owing to its optimal results in several studies that quantified the voids in root canal fillings. ${ }^{1,3,16,17,18,29,30}$ Our scanning procedures were applied using a voxel size of $8.74 \mu \mathrm{m}$, given that voxel size has been indicated as a limiting factor for micro-CT analyses. ${ }^{30}$ It is noteworthy to mention that images with smaller voxel sizes provide greater accuracy in detecting voids in endodontic fillings. ${ }^{17}$
A

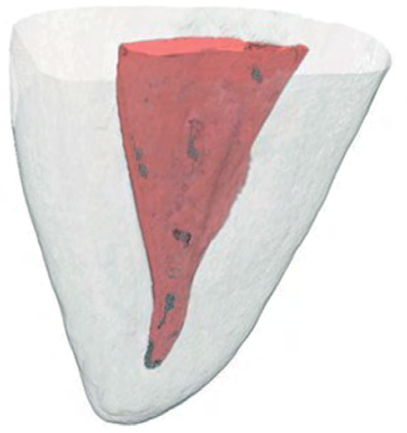

A

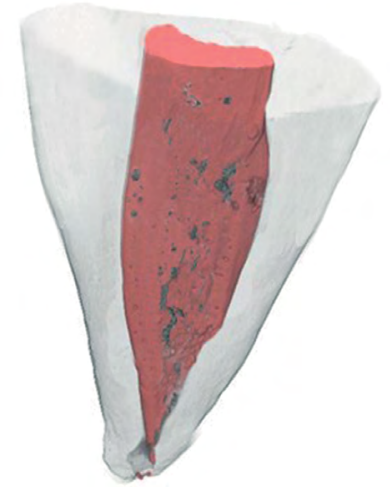

Thermoplastic Technique

B

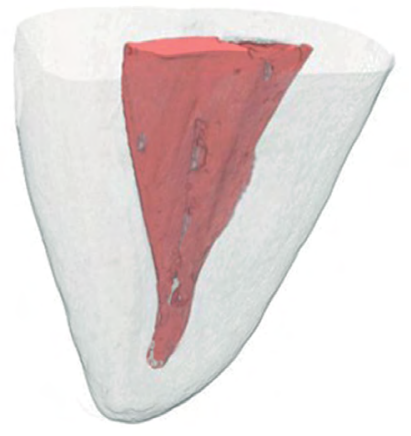

Single-Cone Technique

B

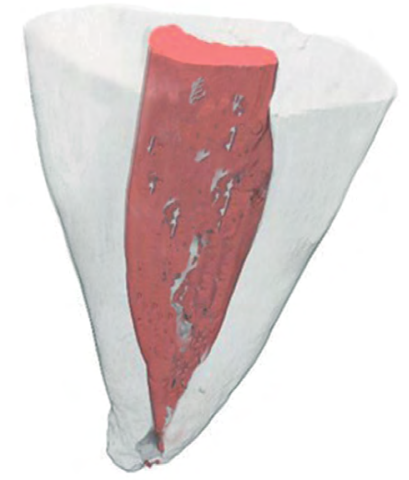

C

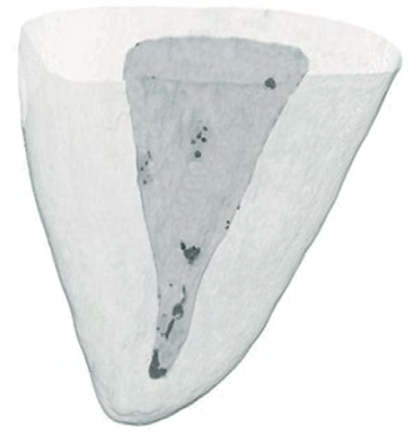

C

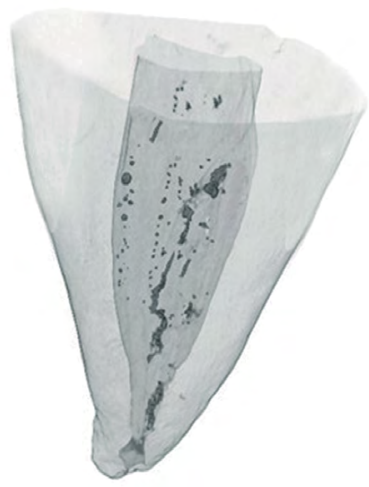

Figure 2. Three-dimensional reconstructions of two flattened distal canals of mandibular molars filled with Bio-C Sealer using thermoplastic or single-cone techniques. Filling material is represented in pink and voids in black. (a) Filling material and voids; (b) filling material; (c) voids. 


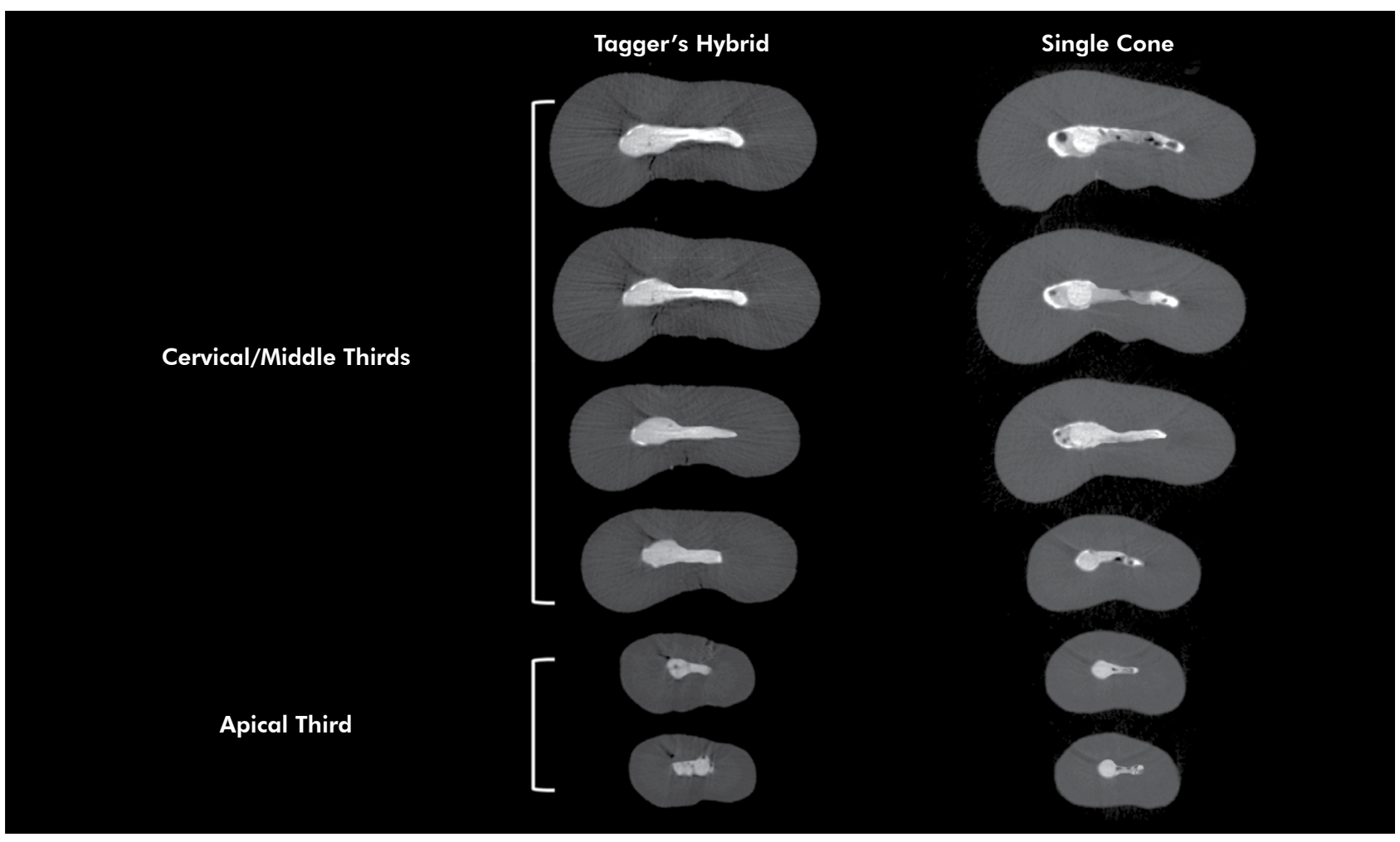

Figure 3. Cross-sectional images of two flattened distal canals of mandibular molars filled with Bio-C Sealer using thermoplastic or single-cone techniques. Filling material (white), voids (black).

Table. Percentage of voids in flattened root canals filled with Bio-C Sealer using thermoplastic or single-cone techniques (means and standard deviations).

\begin{tabular}{lll}
\hline Variable & Thermoplastic & Single-Cone \\
\hline Cervical/Middle & $4.07 \pm 0.59^{\mathrm{b}}$ & $8.99 \pm 1.56^{\mathrm{a}}$ \\
Apical & $9.20 \pm 1.52^{\circ}$ & $8.30 \pm 0.96^{\mathrm{a}}$ \\
\hline
\end{tabular}

Different lowercase letters in same line indicate statistical difference between groups $(p<0.05)$.

Regarding our results of filling ability in flattened root canals, the null hypothesis was partially rejected, since the thermoplastic technique had better filling ability than the single-cone technique in the cervical/middle thirds. Flattened root canals have a larger buccolingual diameter in the cervical region. ${ }^{31}$ In the current study, the root canals filled using the thermoplastic technique provided a homogeneous filling mass, as observed by Fracassi et al. ${ }^{14}$, and a greater extent of filling in the flattened areas. The single-cone technique showed a larger quantity of sealer around the gutta-percha cone (Figure 3). In this technique, the flattened areas are filled with the root canal sealer. However, a thin coat of sealer between the cones and the root canal walls is desirable ${ }^{16}$ to avoid solubilization of the sealer. ${ }^{3,16}$ Since gutta-percha is considered a dimensionally stable material, ${ }^{17}$ this thin film of sealer is considered more favorable in the case of sealers presenting solubility above the values recommended by the ISO 6876:2012 standard, such as Bio-C. ${ }^{22,32}$ Nevertheless, a great amount of sealer is expected when the single-cone technique is used.,16

The suitable filling of the flattened areas when Bio-C Sealer and the thermoplastic technique were used could be attributed to the low percentage of voids and good flow values of Bio-C. ${ }^{22,32}$ These results may be related to the small size of the calcium silicate-based sealer particles (smaller than $2 \mu \mathrm{m}$ ). ${ }^{1,17}$ AH Plus is an epoxy resin-based sealer considered the gold standard regarding physical properties ${ }^{33}$, and is used in different studies together with thermoplastic filling techniques. ${ }^{3,11,12,18}$ However, its properties are negatively affected by increased temperature. ${ }^{16,34,35,36,37}$ Although an increase in temperature changed the physical properties of BioRoot RCS bioceramic sealer 
(Septodont, Saint-Maur-des-Fossés, France), such as flow, film thickness and setting time, these changes did not influence the percentage of voids after heating. ${ }^{16}$ However, AH Plus showed an increase in the voids after heat was applied ${ }^{16}$ Other studies have reported that the chemical composition of calcium silicate-based sealers did not change after heating. ${ }^{35-37}$ In addition, bioceramic sealer EndoSequence BC Sealer HiFlow (Brasseler USA, Savannah, USA) underwent an improvement in flow, viscosity, and film thickness after heating. ${ }^{38}$

Despite the high flowability of Bio-C Sealer, our results show that the percentage of voids for the singlecone technique was $8.99 \%$ in the cervical/middle thirds, an outcome that may reflect negatively on the prognosis of endodontic treatment in clinical practice. On the other hand, no differences in filling ability were found between the thermoplastic and the single-cone techniques in the apical third. The root canals have a cross-section shape that varies according to the root thirds. ${ }^{1}$ In general, at the apical level, the canals have a rounded cross-section, ${ }^{39}$ which could favor adaptation of the gutta-percha master cone. In Tagger's hybrid technique, the McSpadden condenser promotes filling in the cervical and middle thirds. ${ }^{12}$ Similarities have been observed between the thermoplasticized and cold gutta-percha techniques in regard to the quality of sealing and filling in the apical third of oval canals. ${ }^{3,6,40}$

The current research was performed to provide important information for obturation of flattened root canals. Within the limitation of this ex vivo study, none of the techniques promoted complete void-free root fillings. However, the thermoplastic technique associated with the calcium silicate sealer presented better filling of flattened areas in the cervical/middle thirds.

\section{Conclusion}

None of the techniques used with the new calcium silicate-based Bio-C Sealer were associated with void-free fillings in flattened root canals. The thermoplastic technique had a significantly lower percentage of voids than the single-cone technique in the cervical/middle thirds. Both techniques were similar in the apical third.

\section{Acknowledgment}

This study was supported by the Coordenação de Aperfeiçoamento de Pessoal de Nível Superior - Brasil (Capes), Funding Code 001, and by the São Paulo Research Foundation - Fapesp (grant numbers 2016/00321-0, 2017/14305-9, 2017/19049-0 and 2019/22885-0).

\section{References}

1. Celikten B, Uzuntas CF, Orhan Al, Orhan K, Tufenkci P, Kursun S, et al. Evaluation of root canal sealer filling quality using a single-cone technique in oval shaped canals: an In vitro Micro-CT study. Scanning. 2016 Mar-Apr;38(2):133-40. https://doi.org/10.1002/sca.21249

2. García-Guerrero C, Delgado-Rodríguez CE, Molano-González N, Pineda-Velandia GA, Marín-Zuluaga DJ, Leal-Fernandez MC, et al. Predicting the outcome of initial non-surgical endodontic procedures by periapical status and quality of root canal filling: a cohort study. Odontology. 2020 Oct;108(4):697-703. https://doi.org/10.1007/s10266-020-00494-z

3. Keleş A, Alcin H, Kamalak A, Versiani MA. Micro-CT evaluation of root filling quality in oval-shaped canals. Int Endod J. 2014 Dec;47(12):1177-84. https://doi.org/10.1111/iej.12269

4. De-Deus G, Reis C, Beznos D, Abranches AM, Coutinho-Filho T, Paciornik S. Limited ability of three commonly used thermoplasticized gutta-percha techniques in filling oval-shaped canals. J Endod. 2008 Nov;34(11):1401-5. https://doi.org/10.1016/i.joen.2008.08.015

5. Pereira RD, Brito-Júnior M, Leoni GB, Estrela C, Sousa-Neto MD. Evaluation of bond strength in single-cone fillings of canals with different cross-sections. Int Endod J. 2017 Feb;50(2):177-83. https://doi.org/10.1111/iej.12607

6. De-Deus G, Murad C, Paciornik S, Reis CM, Coutinho-Filho T. The effect of the canal-filled area on the bacterial leakage of oval-shaped canals. Int Endod J. 2008 Mar;41(3):183-90. https://doi.org/10.1111/j.1365-2591.2007.01320.x

7. Versiani MA, Pécora JD, Sousa-Neto MD. Flat-oval root canal preparation with self-adjusting file instrument: a micro-computed tomography study. J Endod. 2011 Jul;37(7):1002-7. https://doi.org/10.1016/i.joen.2011.03.017

8. Rivera-Peña ME, Duarte MA, Alcalde MP, Furlan RD, Só MV, Vivan RR. Ultrasonic tips as an auxiliary method for the instrumentation of oval-shaped root canals. Braz Oral Res. 2019 Feb;33:e011. https://doi.org/10.1590/1807-3107bor-2019.vol33.0011 
Effect of obturation technique using a new bioceramic sealer on the presence of voids in flattened root canals

9. Moura-Netto C, Palo RM, Pinto LF, Mello-Moura AC, Daltoé G, Wilhelmsen NS. CT study of the performance of reciprocating and oscillatory motions in flattened root canal areas. Braz Oral Res. 2015;29(1):1-6. https://doi.org/10.1590/1807-3107BOR-2015.vol29.0006

10. Marciano MA, Bramante CM, Duarte MA, Delgado RJ, Ordinola-Zapata R, Garcia RB. Evaluation of single root canals filled using the lateral compaction, tagger's hybrid, microseal and guttaflow techniques. Braz Dent J. 2010;21(5):411-5. https://doi.org/10.1590/S0103-64402010000500006

11. Schäfer E, Nelius B, Bürklein S. A comparative evaluation of gutta-percha filled areas in curved root canals obturated with different techniques. Clin Oral Investig. 2012 Feb;16(1):225-30. https://doi.org/10.1007/s00784-011-0509-z

12. Farias AB, Pereira KF, Beraldo DZ, Yoshinari FM, Arashiro FN, Zafalon EJ. Efficacy of three thermoplastic obturation techniques in filling oval-shaped root canals. Acta Odontol Latinoam. 2016 Apr;29(1):76-81.

13. Tagger M, Tamse A, Katz A, Korzen BH. Evaluation of the apical seal produced by a hybrid root canal filling method, combining lateral condensation and thermatic compaction. J Endod. 1984 Jul;10(7):299-303. https://doi.org/10.1016/S0099-2399(84)80183-1

14. Fracassi LD, Ferraz EG, Albergaria SJ, Veeck EB, Costa NP, Sarmento VA. Evaluation of the quality of different endodontic obturation techniques by digital radiography. Clin Oral Investig. 2013 Jan;17(1):97-103. https://doi.org/10.1007/s00784-012-0675-7

15. Peng L, Ye L, Tan H, Zhou X. Outcome of root canal obturation by warm gutta-percha versus cold lateral condensation: a meta-analysis. J Endod. 2007 Feb;33(2):106-9. https://doi.org/10.1016/i.joen.2006.09.010

16. Heran J, Khalid S, Albaaj F, Tomson PL, Camilleri J. The single cone obturation technique with a modified warm filler. J Dent. 2019 Oct;89:103181. https://doi.org/10.1016/i.jdent.2019.103181

17. Huang Y, Celikten B, Vasconcelos KF, Pinheiro Nicolielo LF, Lippiatt N, Buyuksungur A, et al. Micro-CT and nanoCT analysis of filling quality of three different endodontic sealers. Dentomaxillofac Radiol. 2017 Dec;46(8):20170223. https://doi.org/10.1259/dmfr.20170223

18. Somma F, Cretella G, Carotenuto M, Pecci R, Bedini R, De Biasi M, et al. Quality of thermoplasticized and single point root fillings assessed by micro-computed tomography. Int Endod J. 2011 Apr;44(4):362-9. https://doi.org/10.1111/j.1365-2591.2010.01840.xPMID:21255040

19. Cavenago BC, Duarte MA, Ordinola-Zapata R, Marciano MA, Carpio-Perochena AE, Bramante CM. Interfacial adaptation of an epoxy-resin sealer and a self-etch sealer to root canal dentin using the System B or the single cone technique. Braz Dent J. 2012;23(3):205-11. https://doi.org/10.1590/S0103-64402012000300004

20. Donnermeyer D, Bürklein S, Dammaschke T, Schäfer E. Endodontic sealers based on calcium silicates: a systematic review. Odontology. 2019 Oct;107(4):421-36. https://doi.org/10.1007/s10266-018-0400-3

21. Arias-Moliz MT, Camilleri J. The effect of the final irrigant on the antimicrobial activity of root canal sealers. J Dent. 2016 Sep;52:30-6. https://doi.org/10.1016/i.jdent.2016.06.008

22. Zordan-Bronzel CL, Esteves Torres FF, Tanomaru-Filho M, Chávez-Andrade GM, Bosso-Martelo R, Guerreiro-Tanomaru JM. Evaluation of physicochemical properties of a new calcium silicate-based sealer, Bio-C Sealer. J Endod. 2019 Oct;45(10):1248-52. https://doi.org/10.1016/i.joen.2019.07.006

23. Siqueira JF Jr, Fraga RC, Garcia PF. Evaluation of sealing ability, $\mathrm{pH}$ and flow rate of three calcium hydroxide-based sealers. Endod Dent Traumatol. 1995 Oct;11(5):225-8. https://doi.org/10.1111/j.1600-9657.1995.tb00493.x

24. Vertucci FJ. Root canal anatomy of the human permanent teeth. Oral Surg Oral Med Oral Pathol. 1984 Nov;58(5):589-99. https://doi.org/10.1016/0030-4220(84)90085-9

25. Jou YT, Karabucak B, Levin J, Liu D. Endodontic working width: current concepts and techniques. Dent Clin North Am. 2004 Jan;48(1):323-35. https://doi.org/10.1016/i.cden.2003.12.006

26. Espir CG, Nascimento CA, Guerreiro-Tanomaru JM, Bonetti-Filho I, Tanomaru-Filho M. Radiographic and micro-computed tomography classification of root canal morphology and dentin thickness of mandibular incisors. J Conserv Dent. 2018 Jan-Feb;21(1):57-62. https://doi.org/10.4103/JCD.JCD_230_16

27. Metzger Z, Zary R, Cohen R, Teperovich E, Paqué F. The quality of root canal preparation and root canal obturation in canals treated with rotary versus self-adjusting files: a three-dimensional micro-computed tomographic study. J Endod. 2010 Sep;36(9):1569-73. https://doi.org/10.1016/i.joen.2010.06.003

28. De-Deus G, Simões-Carvalho M, Belladonna FG, Cavalcante DM, Portugal LS, Prado CG, et al. Arrowhead design ultrasonic tip as a supplementary tool for canal debridement. Int Endod J. 2020 Mar;53(3):410-20. https://doi.org/10.1111/iej.13236

29. Orhan K, Jacobs R, Celikten B, Huang Y, de Faria Vasconcelos K, Nicolielo LF, et al. Evaluation of threshold values for root canal filling voids in Micro-CT and Nano-CT images. Scanning. 2018 Jul;2018:9437569. https://doi.org/10.1155/2018/9437569

30. Kim JA, Hwang YC, Rosa V, Yu MK, Lee KW, Min KS. Root canal filling quality of a premixed calcium silicate endodontic sealer applied using gutta-percha cone-mediated ultrasonic activation. J Endod. 2018 Jan;44(1):133-8. https://doi.org/10.1016/j.joen.2017.07.023

31. Filpo-Perez C, Bramante CM, Villas-Boas MH, Húngaro Duarte MA, Versiani MA, Ordinola-Zapata R. Micro-computed tomographic analysis of the root canal morphology of the distal root of mandibular first molar. J Endod. 2015 Feb;41(2):231-6. https://doi.org/10.1016/i.joen.2014.09.024 
32. Torres FF, Zordan-Bronzel CL, Guerreiro-Tanomaru JM, Chávez-Andrade GM, Pinto JC, Tanomaru-Filho M. Effect of immersion in distilled water or phosphate-buffered saline on the solubility, volumetric change and presence of voids within new calcium silicate-based root canal sealers. Int Endod J. 2020 Mar;53(3):385-91. https://doi.org/10.1111/iej.13225

33. Silva Almeida LH, Moraes RR, Morgental RD, Pappen FG. Are premixed calcium silicate-based endodontic sealers comparable to conventional materials? A systematic review of in vitro studies. J Endod. 2017 Apr;43(4):527-35. https://doi.org/10.1016/i.joen.2016.11.019

34. Viapiana R, Guerreiro-Tanomaru JM, Tanomaru-Filho M, Camilleri J. Investigation of the effect of sealer use on the heat generated at the external root surface during root canal obturation using warm vertical compaction technique with System B heat source. J Endod. 2014 Apr;40(4):555-61. https://doi.org/10.1016/i.joen.2013.09.026

35. Camilleri J. Sealers and warm gutta-percha obturation techniques. J Endod. 2015 Jan;41(1):72-8. https://doi.org/10.1016/i.joen.2014.06.007

36. Viapiana R, Baluci CA, Tanomaru-Filho M, Camilleri J. Investigation of chemical changes in sealers during application of the warm vertical compaction technique. Int Endod J. 2015 Jan;48(1):16-27. https://doi.org/10.1111/iej.12271

37. Atmeh AR, AIShwaimi E. The effect of heating time and temperature on epoxy resin and calcium silicate-based endodontic sealers. J Endod. 2017 Dec;43(12):2112-8. https://doi.org/10.1016/i.joen.2017.08.008

38. Chen B, Haapasalo M, Mobuchon C, Li X, Ma J, Shen Y. Cytotoxicity and the effect of temperature on physical properties and chemical composition of a new calcium silicate-based root canal sealer. J Endod. 2020 Apr;46(4):531-8. https://doi.org/10.1016/i.joen.2019.12.009

39. Wu MK, R'oris A, Barkis D, Wesselink PR. Prevalence and extent of long oval canals in the apical third. Oral Surg Oral Med Oral Pathol Oral Radiol Endod. 2000 Jun;89(6):739-43. https://doi.org/10.1067/moe.2000.106344

40. De Deus G, Murad CF, Reis CM, Gurgel-Filho E, Coutinho Filho T. Analysis of the sealing ability of different obturation techniques in oval-shaped canals: a study using a bacterial leakage model. Braz Oral Res. 2006 Jan-Mar;20(1):64-9. https://doi.org/10.1590/S1806-83242006000100012 